\title{
PERSPECTIVE
}

\section{Spare the rod and spoil the eye}

\author{
G B Arden, R L Sidman, W Arap, R O Schlingemann
}

Br J Ophthalmol 2005;89:764-769. doi: 10.1136/bjo.2004.062547

This review presents a new unified view of the pathogenesis of three common causes of acquired retinal degenerative disease-diabetic retinopathy, age related macular degeneration, and retinopathy of prematurity. In these three conditions, angiogenesis has a predominant role in the development of sight threatening pathology.

Angiogenesis is controlled by among other factors the expression of vascular endothelial growth factor (VEGF), which in turn is regulated by absolute and relative lack of oxygen. The severe pathological manifestations of these three conditions are not part of a general underlying disease process because they are peculiar to the eye, and the profound hypoxia that develops in normal retina during dark adaptation (rod driven hypoxia) is an adequate and elegant additional factor to explain their pathogenesis. A large number of experimental reports support this conclusion, although rod driven anoxia is not generally considered as a causal factor in ocular disease. However, the hypothesis can be critically tested, and also suggests novel methods of treatment and prevention of these conditions that may be simpler and more inexpensive than current therapies and that have a smaller potential for adverse effects.

See end of article for authors' affiliations

Correspondence to: G B Arden, Henry Wellcome Laboratories, Applied Vision Research Centre, Department of Optometry and Visual Science, City University, Northampton Square, London $\mathrm{ECIV} \mathrm{OHB}, \mathrm{UK}$; g.arden@city.ac.uk

Accepted for publication 14 January 2005
$\mathrm{T}$ hree common blinding diseases-diabetic retinopathy (DR), retinopathy of prematurity (ROP) in oxygen treated neonates, and age related macular degeneration (ARMD)-are peculiar to the eye. The hallmark of these conditions is angiogenesis, the formation of new blood vessels, but the processes that give rise to them are apparently confined to the retina. Recent discoveries have detailed various mechanisms of angiogenesis in the eye, in particular the role of hypoxia induced vascular endothelial growth factor (VEGF), ${ }^{1}$ so it is now becoming meaningful to ask what local factors might account for the especial damage to the retina in $\mathrm{DR}, \mathrm{ROP}$, and ARMD. One feature that distinguishes the retina from other parts of the central nervous system and from other organs is the presence of large numbers of specialised photoreceptor cells-140000 000 rods and 6000000 cones. We suggest that the special susceptibility of the retina is caused by two properties of photoreceptor cells-their signalling transduction properties ${ }^{2-4}$ and the proximal growth and distal shedding of their outer segments throughout life. ${ }^{5}$ We have constructed a hypothesis about causation of DR, ROP, and
ARMD that leads to strong predictions about epidemiology and treatment, which in some instances have already been empirically tested. The key idea we wish to bring to the readers' attention is that the dark adapted retina is normally hypoxic because of the great oxygen demands of rods. Any embarrassment of the supply of oxygen, whether it be caused by capillary basement membrane thickening, capillary non-perfusion, or a relative impermeability of Bruch's membrane or indeed any other pathology, causes the zone of reduced oxygen tension to spread from the photoreceptor layer both proximally and distally. This anoxia is a very important but hitherto relatively little considered contributory causal factor in the three conditions discussed below, though of course, local factors also play a part, and DR and ARMD are known to be multifactorial.

\section{DIABETIC RETINOPATHY}

Histopathology of the condition peculiar to the eye

Diabetes, experimental and clinical, selectively damages retinal microvessels. Elsewhere, the diabetic state causes thickening of capillary basement membrane, but only in retinal blood vessels is there loss of pericytes, and swelling and damage to capillary endothelial cells that result in the capillary dropout, microaneurysms, leakage, cellular damage, and new blood vessel growth that characterises $\mathrm{DR}^{6}{ }^{6}$ This indicates that local factors unique to the retina provoke $\mathrm{DR}^{6}$ although retina is often considered "an approachable part of the brain." ${ }^{\prime 7}$ The main difference between retina and brain tissue is, of course, the photoreceptors.

\section{Energy requirements of photoreceptors}

Their signal transduction mechanism, found in no other neuron, is very energy demanding. In darkness the surface membrane of the rod outer segment is leaky, and water and sodium enter, to be extruded by pumps in the inner segment. Light seals the leaks in the outer segment, reduces or stops the dark current and promptly halts the pump action, reducing metabolism and oxygen uptake. The maximum magnitude of the dark current under strict dark adapted conditions indicates that the rod circulates its entire cytosol volume in 30 seconds, ${ }^{8}$ and this process produces more heat and consumes more oxygen than any function in any other cell. Although the

Abbreviations: AGEs, advanced glycation end products; $A R M$, age related maculopathy; $A R M D$, age related macular degeneration; CNV, choroidal neovascularisation; $D R$, diabetic retinopathy; PRP, panretinal photocoagulation; ROP, retinopathy of prematurity; VEGF, vascular endothelial growth factor 
retina has a double blood supply from the central artery and from the choroid, the photoreceptor layers are avascular, and the oxygen supply is normally barely sufficient. This explains why dark adapted sensitivity in normal people begins to drop when there is a slight reduction of inspired oxygen, equivalent to ascending to 3000 feet (914 metres), ${ }^{9}$ and loss of dark adaptation is the first symptom in a variety of pathological conditions, ranging from polycythaemia vera to partial carotid occlusion, before other functions fail. ${ }^{10-12}$

\section{Retinal anoxia in dark adaptation is present in normal eyes}

Experiments with oxygen microelectrodes in normal eyes show a precipitous drop in partial oxygen pressure $\left(\mathrm{pO}_{2}\right)$ as the microelectrode passes from the level of the choroidal blood vessels to fall to a minimum in the vicinity of the rod mitochondria and the photoreceptor cell synapses in the outer plexiform layer. ${ }^{13}{ }^{14}$ In dark adapted eyes this minimum $\mathrm{pO}_{2}$ tension is zero, but even during a brief flash of light it reaches $30 \mathrm{~mm} \mathrm{Hg} .{ }^{15}$ Unlike other brain cells, rods can apparently function in such ultra low oxygen environments but their remarkably intense activity in darkness reduces the $\mathrm{pO}_{2}$ of the inner retina, a region served by blood vessels that penetrate inward from the vitreal surface but do not actually reach the rod cells. Therefore, when rods operate at maximum activity, a relative anoxia may develop in the inner portions of the retina in disease states with less than optimal oxygen supply.

\section{Relative impairment of oxygen supply in early (grade 0 and 1) DR}

Clinical DR appears to develop years after the condition is diagnosed. But during the preclinical period, although the fundus is normal (stage 0), psychophysical and electrophysiological experiments demonstrate that anomalies are developing, especially in rod vision (reviewed by $\operatorname{Arden}^{16}$ ). It has been shown that several of these losses can be promptly, though only partially, reversed by inhaling oxygen from a face mask. ${ }^{17-19}$ Therefore, even at stage 0 , there must be a degree of oxygen lack in the retina of people with diabetes. Thus, the loss of dark adaptation in people with diabetes at stage 0 is explicable. Diabetes causes a series of slight changes in the circulation: glycosylated haemoglobin has a Michaelis-Menton curve shifted slightly to the right, basement membranes thicken, and red blood cell walls stiffen slightly, reducing ease of transport through the capillaries. In most tissues, these modifications would be of little consequence, but the retina has very little reserve capacity, and slight reductions in oxygen supply would tend to decrease the $\mathrm{pO}_{2}$. This cannot fall below the zero level found in the region of the rod mitochondria, but proximal and distal to this point $\mathrm{pO}_{2}$ will be reduced. This concept is supported by findings in diabetic cats, where retinal oxygen tension is reduced relative to normal, even in regions with no fluorescein angiographic evidence of actual capillary dropout. $^{20}$

\section{Production of cytokines in diabetic retina enhanced by hypoxia}

Hyperglycaemia is the first signal to trigger the onset of DR and the cascade of metabolic and biochemical changes. ${ }^{21}$ Hyperglycaemia is associated with apoptosis of neuronal and vascular cells in the retina. ${ }^{22}{ }^{23}$ High levels of intracellular glucose cause, among other changes, a state of "pseudohypoxia" in retinal cells. ${ }^{24}$ (Pseudo)hypoxia may upregulate factors such as vascular endothelial growth factor A (VEGFA). ${ }^{1}$ VEGF is a prime regulator of angiogenesis and vascular permeability (reviewed by Ferrara ${ }^{25}$ ), but may have vasoprotective and neuroprotective functions as well. Evidence is available for a role of VEGF-A in the early stage of DR, as retinal VEGF expression by activated Müller cells is increased a few weeks after the onset of diabetes in rats. ${ }^{25-31}$ Intracellular pseudohypoxia, high levels of glucose and advanced glycation end products (AGEs) all induce increased VEGF expression in cells in vivo and in vitro. ${ }^{21-33}$ We suggest that in preclinical DR, the increased anoxia associated with complete dark adaptation is a crucial and necessary driving force of VEGF upregulation, in synergy with the consequences of chronic hyperglycaemia. Therefore, even in the preclinical phase of diabetic retinopathy, dark adapted rods are instrumental in the increase of VEGF expression. VEGF overexpression may reflect a stress response enabling survival of vascular and neuronal cells, but it also induces early bloodretinal barrier breakdown, ${ }^{34-36}$ leucocyte adhesion to retinal vessels, ${ }^{37}$ swelling of endothelial cells, ${ }^{38}$ and proliferation of endothelial cells. ${ }^{39}$

Once this increase is established, repeated insults of endothelial apoptosis and reactive proliferation probably cause replicative senescence of endothelial cells resulting in the capillary dropout seen in clinical DR, which, by itself, may leads to a vicious circle of ischaemia, VEGF production, endothelial swelling and capillary non-perfusion, reinforcing the production of anoxia. ${ }^{30-39}$ This scheme of events can easily be envisaged against the background of rod induced anoxia acting as an independent driving force. Later, when clinical DR is established, and widespread vascular leakage, capillary dropout, and neovascularisation can be seen, the anoxia associated with DR is evident (see fig 1). The part played by VEGF-A and its receptors in this clinical stage is very well documented. ${ }^{1}$

\section{Evidence that DR is caused by local anoxia}

Evidence is plentiful for the suggestion that "rod driven anoxia" triggers the changes that cause DR. As predicted, DR does not occur in patients who have diabetes and retinitis

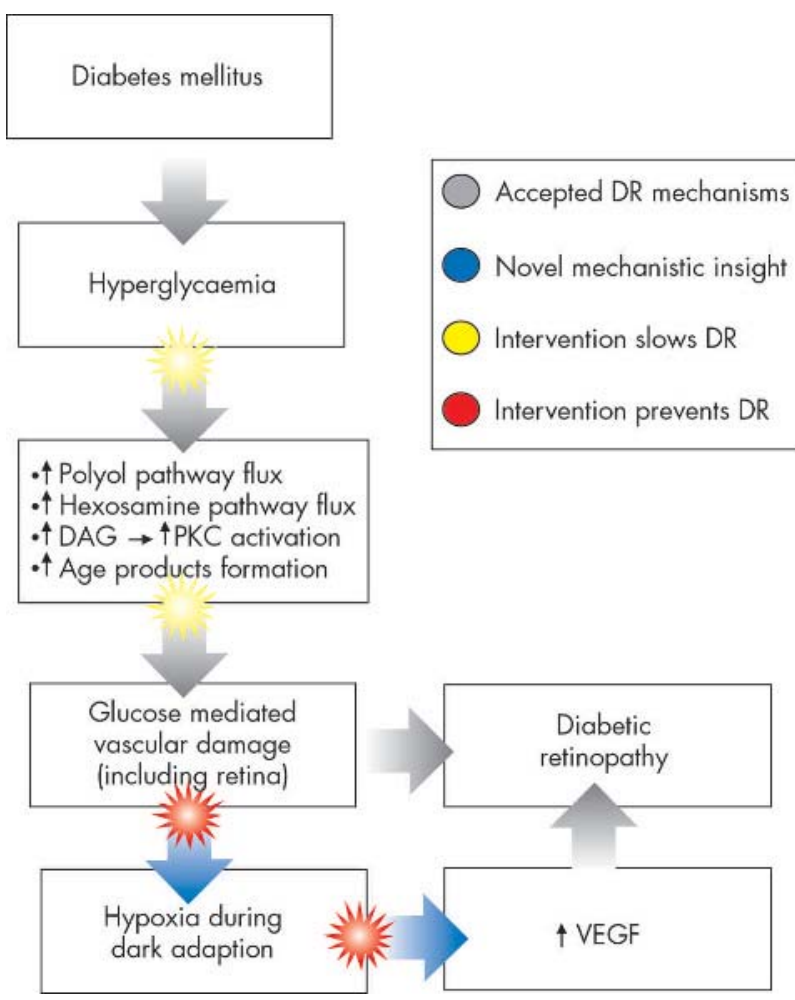

Figure 1 Physiopathological scheme for the development of diabetic retinopathy. DR, diabetic retinopathy; DAG, diacylglycerol; PKC, protein kinase C; AGE, advanced glycation end product; VEGF, vascular endothelial growth factor. 
pigmentosa ${ }^{16}$ because rod outer segments are reduced in this condition. Proliferative DR may even regress in the presence of retinal degenerations such as retinitis pigmentosa. ${ }^{40}$ In the mitochondrial disorder MIDD 3243, which begins in adult life, diabetes is characteristic, and DR commonly occurs unless a retinal degeneration also develops. ${ }^{41-43}$ Some people with longstanding diabetes (types 1 and 2) develop no signs of DR at all. In a group of these, it has been shown that the upregulating effect of anoxia on blood white cell VEGF production is greatly reduced. ${ }^{44}$ However, the best evidence of the importance of anoxia is (i) the success of the common treatment of DR, panretinal photocoagulation, which was introduced to destroy retinal tissue thought to be liberating "toxins," but which may work simply by destroying enough rods to increase retinal $\mathrm{pO}_{2}{ }^{45}$ and (ii) the recent report that breathing oxygen from nasal tubes for 3 months improves visual acuity and partially reverses the appearance of the macula in cases of diabetic maculopathy. ${ }^{46}$ Such treatment only provides $<10 \%$ more oxygen to the retina. An alternative strategy, light adaptation during sleep, could reduce the oxygen requirement by $\sim 50 \%$ and should therefore be at least as effective. ${ }^{47}$

\section{Other causes of DR, and predictions arising from the new hypothesis}

Of course several systems contribute to diabetic retinopathy. The effects of glucose and insulin are well known, and the polyol pathway, and pseudohypoxia that is associated with $\mathrm{NAD}-\mathrm{NADH}$ levels also can cause retinal damage. In experimental oxygen induced retinopathy, knockout of insulin receptors, which are indirectly necessary for VEGF activity, reduces vascularisation by $50 \%,{ }^{48}$ but knockout of rods in mice prevents any vascular proliferation in this model. ${ }^{40}$ Almost the only time human rods ever dark adapt (and maximise their oxygen needs) in our electrically lit modern environment is during sleep. Our hypothesis predicts that if people with diabetes and grade $0-\mathrm{I}$ retinopathy were to sleep in light levels of $1-10 \mathrm{~cd} / \mathrm{m}^{2}$, sufficient light would pass through the lids to protect against DR. (Consideration of the quantity of light required can be found in the paper by Arden $^{16}$ ) Another testable prediction is that elderly people with diabetes who suffer from sleep apnoea would have considerably more DR than those who do not.

\section{RETINOPATHY OF PREMATURITY}

Rod driven anoxia is also the probable cause of ROP. In a well known mouse model of $\mathrm{ROP}^{49}$ pups are placed in $75 \%$ oxygen from postnatal day P7 to P12. For the first two thirds of this period the eyelids are still closed, the rod outer segments have just begun to form, and the retina is growing and becoming vascularised. However, the hyperoxia results in an underdevelopment of retinal vasculature. Return to normal air at P12 coincides with the rapid development of rod outer segments, an increased retinal oxygen demand, and a large rise in retinal VEGF, so that by P17-21, a prominent proliferative retinopathy develops. However, if the same experiment is performed with mutant mice in which photoreceptor cells degenerate as their rod outer segments are differentiating, no proliferative retinopathy is found. ${ }^{40}$ Thus, in this model the activity or presence of rods is necessary for ROP to develop.

Despite great advances in paediatric care, ROP remains a relatively frequent complication of prematurity. It is customary to maintain premature infants in well illuminated intensive care units, though ordinary care units typically are maintained in reduced illumination. By analogy with the mouse experiments, our hypothesis suggests this is precisely the wrong arrangement. When neonates are maintained in a high oxygen environment, they should be exposed to as little light as possible to encourage growth of the retinal vessels. Red light (wavelength $>660 \mathrm{~nm}$ ) is scarcely absorbed by retinal rods; general and local illumination with red light emitting diodes should suffice for all necessary manipulations. When the neonate is returned to a normal air environment, the room should be brightly lit, so that the oxygen demand of the still immature eye is minimised. Brief trials would show whether this regime results in less ROP. Experimental evidence exists supporting our hypothesis. In the mouse model, ROP is less prominent in litters kept continuously in darkness than those kept continuously in light. ${ }^{50}$ In a multicentre trial in neonates, ${ }^{51}$ goggles absorbing $97 \%$ of ambient illumination were fitted at random to half of the babies. In this trial, the investigators' hypothesis that bright light is harmful in neonates could not be confirmed, as predicted by our hypothesis. That this trial did not show an opposite effect, consistent with our hypothesis, may be because of the amount of light passing through the goggles and the eyelids: with eyes open, retinal illumination was at photopic levels $\left(4 \mathrm{~cd} / \mathrm{m}^{2}\right)$ behind the goggles. Because eyelids in neonates absorb less light than in adults, even with the lids closed, the retinal illumination in the "goggled" babies could have been sufficient for a light adapted state and have a protective effect against rod driven anoxia. In fact, the percentage of "goggled" babies who had ROP was slightly higher when the goggles were fitted early. Thus, the results of this clinical trial are at least consistent with our hypothesis.

\section{AGE RELATED MACULAR DEGENERATION Pathology}

Age related maculopathy is a multifactorial condition. Though there is a genetic component, ${ }^{52}$ the rapidly increasing prevalence suggests the importance of environmental factors, ${ }^{52-56}$ and this is also indicated by histopathological studies (see below). The natural history shows that after the age of 55, increasing numbers of people develop large "soft" drusen, and the number of these increase with time. The drusen are seen in the posterior pole, often in a ring peripheral to the macula. ${ }^{56}$ The drusen are the clinically visible indicators of a collection of abnormal material between Bruch's membrane and the retinal pigment epithelium (RPE) and Bruch's membrane and the choroid, known as basal laminar and basal linear deposits, respectively. ${ }^{57-59}$ The RPE also becomes loaded with lipofuscin granules, resulting from phagocytosis and incomplete digestion of rod outer segment fragments. ${ }^{60-64}$ The volume of shed outer segments is $\sim 2 \mu \mathrm{m}^{3}$ per rod per day (see Young and $\mathrm{Bok}^{5}$ ) and $\sim 30$ outer segments contact each RPE cell. Analysis of the material contained in drusen ${ }^{59} 60$ shows it contains highly oxidised lipids, suggesting their formation by reactive oxygen species in senescent RPE cells that can no longer properly digest phagocytosed rod outer segments. ${ }^{61-64}$ This failure leads to the accumulation of the deposits in both the "dry" and "wet" forms of ARMD. ${ }^{61}$ At the same time, abnormalities occur in the choroid. ${ }^{65}{ }^{66}$ Thus, ARMD appears to be another disease whose manifestations are caused by local retinal factors. ${ }^{67}$ Visual function is affected early in the condition. ${ }^{68-79}$ Dark adaptation is slowed and less complete even in the early stages, and blue cone vision is also affected. ${ }^{77-79}$ Like DR, there is an asymptomatic "preclinical" stage but during this stage, drusen can be seen, pigment irregularities develop, and subtle losses of rod and cone function occur. The histologically verified loss of rods in the region of their highest density ${ }^{80}$ suggested that the condition is caused by the death of rods, but at a comparable stage there is also evidence of an obstructive barrier between choroid and RPE, ${ }^{78-84}$ which hinders the diffusion of oxygen from the choroid. Abnormal biochemical and immunocytological findings have been reported at this phase. With the loss of rods, irregularities and patchy diminution of choroidal 
blood flow may be seen in ageing eyes. ${ }^{66} 6783$ The causal relations of these several findings are obscure. The primary disorder may be a defect in the RPE. Curcio ${ }^{80}$ raises the possibility that rod death leads to loss of a trophic factor necessary for normal cone function. However, in various other forms of night blindness, with absent or very reduced rod function, macular degeneration does not occur as an early event. The early stage (now often called age related maculopathy, ARM) occurs with little obvious symptomatology, but after some time, subjective visual disturbance occurs, associated with a change in retinal appearance. In the "dry" form, a limited retinal geographic atrophy eventually occurs. The fovea can be spared. In other cases, there is growth of new vessels from the choroid through Bruch's membrane into the subretinal space, local oedema, and leakage (choroidal neovascularisation $(\mathrm{CNV})$ ). At this stage there is metamorphopsia, considerable reduction in acuity and obvious retinal damage. At such a stage the condition is often termed age related macular degeneration.

\section{Cytokines in age related maculopathy}

In development, and during adult life, the RPE controls the vascularity of the choroids. ${ }^{1}$ There is a normal strong polarisation of the secretion of VEGF basolaterally, ${ }^{84}$ and this paracrine relation with the choriocapillaris ${ }^{1}$ is disturbed by changes associated with ageing. ${ }^{81}$ In ageing, Bruch's membrane thickens and becomes lipid laden, ${ }^{82}$ decreasing hydraulic conductivity and aqueous diffusion to the choroid. Even in the earliest stages of ARM, there may be retinal and RPE hypoxia because of the high metabolic requirements of the retina. Any diminution of VEGF secretion into the choroid will cause choriocapillaris atrophy, which indeed is observed in aged human eyes (reviewed by Witmer et al ${ }^{1}$ ), and reduce the oxygen supply to the adjacent RPE and retina. Thus ageing changes may enter a vicious circle, with alteration in RPE function eventually leading to further relative atrophy of choriocapillaris, the deposition of basal deposits, the relative impermeability of Bruch's membrane, and documented loss of rod and blue cone function. At this clinical stage considerable retinal and RPE hypoxia upregulates VEGF, but transfer to the choriocapillaris is so reduced that a higher critical concentration may develop in the outer retina, or proximal to Bruch's membrane, triggering choroidal neovascularisation. ${ }^{84-87}$ Alternatively, the anoxia can cause death of RPE and retina in geographic atrophy. Although many factors contribute to this sequence of change ${ }^{86}$ critical participants are (i) abnormally metabolised material shed from the rods (responsible for the barrier to fluid transfer), and (ii) the extreme metabolic demands of rods (contributing heavily to anoxia and VEGF upregulation). This suggests that were rods to be absent the changes associated with ARM would develop more slowly.

\section{Effects of lasering and panretinal photocoagulation on ARM}

A small number of scattered laser burns in ARM reduces drusen, and can stabilise retinal function. ${ }^{778-96}$ The Choroidal Neovascularisation Prevention Trial $(\mathrm{CNPT})^{96}$ also determined this, but the immediate high incidence of neovascularisation following their protocol led to termination of patient recruitment. However, after 5 years, the patients' vision was not worse than controls, so that some retardation in development of ARMD must have occurred. The longest small trial shows that the production of "wet" ARMD is reduced 8 years after lasering. The mechanism whereby such light lasering removes drusen (at least temporarily), and apparently arrests the progress of retinal degeneration is not fully established. However, there is evidence that many more retinal burns, applied to people with much milder ARM, can have beneficial outcome. In people with type 2 diabetes ARM occurs at a similar frequency to normal controls. ${ }^{97}$ However, after panretinal photocoagulation (PRP) there is a marked reduction in the prevalence of wet and dry $\mathrm{ARMD}^{98}$ and there is much anecdotal evidence to the same effect. All this suggests that an important factor in the development of ARM may be a relative anoxia in the outer part of the retina/RPE complex. The reported increase in cytokine formation ${ }^{84}{ }^{87}$ is of course consistent with a local relative anoxia. The success of two differing anti-VEGF therapies ${ }^{99} 100$ in improving vision and fundus appearances in patients with ARMD also indicates the importance of this cytokine in the development of the disease, and provides further indications of the importance of relative anoxia. Anoxia would necessarily be worse during periods of dark adaptation and, as in DR, it is possible that the condition would progress more slowly if such periods were avoided.

In summary, we propose that the huge numbers of peripheral rods are major driving factors in hypoxic retinopathies, and propose light adaptation during sleep, or early prophylactic inactivation or laser culling as a therapy.

\section{ACKNOWLEDGEMENTS}

Supported by the Edward en Marianne Blaauw Fonds.

\section{Authors' affiliations}

G B Arden, Henry Wellcome Laboratories, Applied Vision Research Centre, Department of Optometry and Visual Science, City University, London ECIV OHB, UK

R L Sidman, Neurology Department, Beth Israel Deaconess Medical Center, Harvard Medical School, Boston, MA, USA

W Arap, The University of Texas MD Anderson Cancer Center, Houston, TX 77030, USA

R O Schlingemann, Medical Retina Unit, Department of Ophthalmology, Academic Medical Center, PO Box 22700, 1100 DE Amsterdam, Netherlands

\section{REFERENCES}

1 Witmer AN, Vrensen GFJM, Van Noorden CJF, et al. Vascular endothelial growth factors and angiogenesis in eye disease. Prog Retin Eye Res 2003;22:1-29.

2 Pugh ENJ, Nikonov S, Lamb TD. Molecular mechanisms of vertebrate photoreceptor light adaptation. Curr Opin Neurobiol 1999;9:410-18.

3 Ebrey T, Koutalos Y. Vertebrate photoreceptors. Prog Ret Eye Res $2001 ; 20: 49-94$.

4 Hurley JB. Commentary. Shedding light on adaptation. J Gen Physiol 2002;119:125-8.

5 Young, RW, Bok D. Participation of the retinal pigment epithelium in the rod outer segment renewal process. J Cell Biol 1969;42:392-403.

6 Kern TS, Engerman RL. Capillary lesions develop in retina rather than in cerebral cortex in diabetes and experimental galactosaemia. Arch Ophthalmol 1996;114:306-7.

7 Dowling JE. The retina: an approachable part of the brain. Cambridge, MA: Belknap Press of Harvard University Press, 1987:282.

8 Hagins WA, Ross PD, Tate RI, et al. Transduction heats of retinal rods. Tests of the role of cGMP by pyroelectric calorimetry. Proc Natl Acad Sci USA 1989;86:1224-8

9 McFarland RA, Evans JN. Dark adaptation and reduced oxygen tension. Am J Physiol 1939;127:37-50.

10 Havelius U, Bergqvist D, Falke $P$, et al. Impaired dark adaptation in symptomatic carotid artery disease. Neurology 1997;49:1353-9.

11 Havelius U, Bergqvist D, Hindfelt $B$, et al. Improved dark adapation after carotid endarterectomy. Evidence of a long-term ischaemic penumbra. Neurology 1997;49:1360-4

12 Havelius $\mathrm{H}$, Berglund S, Falke $\mathrm{P}$, et al. Impaired dark adaptation in polycythaemia . Improvement after treatment. Acta Ophthalmol Scand 2000;78:53-7.

13 Linsenmeier RA. The effect of light and darkness on oxygen distribution and consumption in the cat retina. J Gen Physiol 1986;88:521-42.

14 Braun RD, Linsenmeier RA. Oxygen consumption in the inner and outer retina of the cat. Invest Ophthal Vis Sci 1995;36:542-54.

15 Haugh LM, Scheidt LA, Griff ER, et al. Light evoked oxygen responses in the toad retina. Exp Eye Res 1995;61:73-81.

16 Arden GB. The absence of diabetic retinopathy in patients with retinitis pigmentosa: Implications for pathophysiology and possible treatment. $\mathrm{Br} J$ Ophthalmol 2001;85:366-70.

17 Harris A, Danis RP, Evans S, et al. Hyperoxia improves contrast sensitivity in early diabetic retinopathy. $\mathrm{Br} J$ Ophthalmol 1996;80:209-13. 
18 Dean F, Dornhorst A, Arden GB. Partial reversal of protan and tritan colour defects with inhaled oxygen in insulin dependent diabetic subjects. Br J Ophthalmol 1997;81:27-30.

19 Drasdo N, Chiti Z, Owens DR, et al. Effect of darkness on inner retinal hypoxia in diabetes. Lancet 2002;359:2251-3.

20 Linsenmeier RA, Braun RD, McRipley MA, et al. Retinal hypoxia in long term diabetic cats. Invest Ophthalmol Vis Sci 1998;39:1647-58.

21 Brownlee M. Biochemistry and molecular cell biology of diabetic complications. Nature 2001;414:813-20.

22 Mitzutani M, Kern TS, Lorenzi M. Accelerated death of retinal microvascular cells in human and experimental diabetic retinopathy. J Clin Invest 1996;97:2883-90.

23 Gardner TW, Antonetti DA, Barber AJ, et al. Diabetic retinopathy: more than meets the eye. Survey Ophthalmol, 2002;47(Suppl 2) S253-62.

24 Williamson JR, Chang K, Frangos $M$, et al. Hyperglycemic pseudohypoxia and diabetic complications. Diabetes 1993;42:801-13.

25 Ferrara N. Vascular endothelial growth factor: molecular and biological aspects. Current Topics in Microbiology and Immunology 1999;237:1-30.

26 Lu M, Kuroki M, Amano S, et al. Advanced glycation end products increase retinal vascular endothelial growth factor expression. J Clin Invest 1998;101:1219-24.

27 Sone H, Kawakami Y, Okuda Y, et al. Ocular vascular endothelial growth factor levels in diabetic rats are elevated before observable retinal proliferative changes. Diabetologia 1997;40:726-30.

28 Murata T, Nakagawa K, Khalil A, et al. 1. The relation between the expression of VEGF and the breakdown of BRB in diabetic rat retinas. Lab Invest 1994;74:819-25.

29 Amin RH, Frank RN, Kennedy A, et al. Vascular endothelial growth factor is present in glial cells of the retina and optic nerve of human subjects with nonproliferative diabetic retinopathy. Invest Ophthalmol Vis Sci 1997;38:36-47.

30 Gilbert RE, Vranes D, Berka JL, et al. Vascular endothelial growth factor and its receptors in control and diabetic rat eyes. Lab Invest 1998;78:1017-27.

31 Hammes HP, Lin J, Bretzel RG, et al. Upregulation of the vascular endothelial growth factor/vascular endothelial growth factor receptor system in experimental background diabetic retinopathy of the rat. Diabetes 1998;47:401-6.

32 Joussen AM, Poulaki V, Qin W, et al. Retinal vascular endothelial growth factor induces intercellular adhesion molecule-1 and endothelial nitric oxide synthase expression and initials early diabetic retinal leucocyte adhesion in vivo. Am J Pathol 2002;160:501-9.

33 Segawa Y, Shirao Y, Yamagishi S, et al. Upregulation of vascular endothelial growth factor mRNAs in spontaneously diabetic rats without ophthalmoscopic retinopathy. A possible participation of advanced glycation end products in the early phase of diabetic retinopathy. Ophthalmic Res 1998;30:333-9.

34 Hofman P, Van Blijswijk BC, Gaillard PJ, et al. Endothelial cell hypertrophy induced by vascular endothelial growth factor in the retina: new insights into the pathogenesis of capillary nonperfusion. Arch Ophthalmol 2001;119:861-6.

35 Quam T, Xu Q, Joussen AM, et al. VEGF-initiated blood retinal barrier breakdown in early diabetes. Invest Ophthalmol Vis Sci 2001;42:2408-13.

36 Nomura M, Yamagishi S, Harada S, et al. Possible participation of autocrine and paracrine vascular endothelial growth factors in hypoxia-induced proliferation of endothelial cells and pericytes. J Biol Chem 1995;270:28316-24

37 Tolentino MJ, Miller JW, Gragoudas ES, et al. Intravitreous injections of vascular endothelial growth factor produce retinal ischemia and microangiopathy in an adult primate. Ophthalmology 1996;103:1820-8.

38 Hofman P, Blaauwgeers HG, Vrensen GFJM, et al. Role of VEGF-A in endothelial phenotypic shift in human diabetic retinopathy and in VEGF-A induced retinopathy in monkeys. Ophthalmic Res 2001;33:156-62.

39 Sharma NK, Gardiner TA, Archer DB. A morphologic and autoradiographic study of cell death and regeneration in the microvasculature of normal and diabetic rats. Am J Ophthalmol 1985;100:51-60.

40 Lahdenranta J, Pasqualini R, Schlingemann RO, et al. An anti-angiogenic state in mice and humans with retinal photoreceptor degeneration. Proc Natl Acad Sci USA 2001;98:10368-73.

41 Smith PR, Bain SC, Good PA, et al. Pigmentary retinal dystrophy and the syndrome of maternally inherited diabetes and deafness caused by the mitochondrial DNA 3243 tRNA Leu A to G mutation. Adv Exp Med Biol 1999;169:661-70.

42 Sue CM, Mitchell P, Crimmins DS, et al. Pigmentary retinopathy associated with the mitochondrial DNA 3243. Neurology 1997:49:1013-17.

43 Holmes-Walker DJ, Mitchell P, Boyages SC. Does mitochondrial genome mutation in subjects with maternally inherited diabetes and deafness decrease severity of diabetic retinopathy? Diabetic Med 1998;15:946-52.

44 Marsh S, Nakhoul FM, Skorecki K, et al. Hypoxic induction of vascular endothelial growth factor is markedly decreased in diabetic individuals who do not develop retinopathy. Diabetes Care 2000;23:1375-80.

45 Yu DY, Cringle SJ. Oxygen distribution and consumption within the retina in vascularised and avascular retinas and in animal models of retinal disease. Prog Retina Eye Res 2001;20:175-208.

46 Nguyen QD, Shah SM, van Anden E, et al. Supplemental oxygen improves diabetic macular edema: a pilot study. Invest Ophthalmol Vis Sci 2004;45:617-24.

47 Arden GB, Schlingeman RO. Oxygen and diabetic retinopathy. e-publication Invest Ophthalmol Vis Sci 5 Jan 2005 (comment on ref 46).

48 Kondo T, Vicent D, Suzuma K, et al. Knockout of insulin and IGF-1 receptors on vascular endothelial cells protects against retinal neovascularization. J Clin Invest 2003;111:1817-19.
49 Smith LE, Wesolowski E, McLellan A, et al. Oxygen-induced retinopathy in the mouse. Invest Ophthalmol Vis Sci 1994;35:101-11.

50 Wesolowski E, Smith LE. Effect of light on oxygen-induced retinopathy in the mouse. Invest Ophthalmol Vis Sci 1994;35:112-19.

51 Reynolds JD, Hardy RJ, Kennedy KA, et al. Lack of efficiacy of light reduction in preventing retinopathy of prematurity. New Engl J Med 1998;338:1572-6.

52 Zack DJ, Dean M, Molday RS, et al. What can we learn about age-related macular degeneration from other retinal diseases? Mol Vis 1999:5:30.

53 Darzins $\mathbf{P}$, Mitchell P, Heller RF. Sun exposure and age-related macular degeneration. An Australian case-control study. Ophthalmology 1997; 104:770-6

54 Cai J, Nelson KC, Wu M, et al. Oxidative damage and protection of the RPE. Prog Retin Eye Res 2000;19:205-21.

55 Beatty S, Koh H, Phil M, et al. The role of oxidative stress in the pathogenesis of age-related macular degeneration. Surv Ophthalmol 2000;45:115-34

56 Zarbin MA. Age-related macular degeneration: review of pathogenesis. Eur J Ophthalmol 1998:8:199-206.

57 Green WR. Histopathology of age-related macular degeneration. Mol Vis 1999;5:27.

58 Lutty G, Grunwald J, Maiji AB, et al. Changes in choriocapillaris and retinal pigment epithelium in age-related macular degeneration. Mol Vis, 1999;5:35

59 Adler R, Curcio C, Hicks D, et al. Cell death in age-related macular degeneration. Mol Vis 1999:5:31.

60 Nguyen-Legros J, Hicks D. Renewal of photoreceptor outer segments and their phagocytosis by the retinal pigment epithelium. Int Rev Cytol 2000; 196:245-313

61 Marmorstein AD, Finnemann SC, Bonilha VL, et al. Morphogenesis of the retinal pigment epithelium: toward understanding retinal degenerative diseases. Ann NY Acad Sci 1998;857:1-12

62 Hageman GS, Luthert PJ, Victor Chong NH, et al. An integrated hypothesis that considers drusen as biomarkers of immune-mediated processes at the RPE-Bruch's membrane interface in aging and age-related macular degeneration. Prog Retin Eye Res 2001;20:705-32.

63 Gu X, Meer SG, Miyagi M, et al. Carboxyethylpyrrole protein adducts and autoantibodies, biomarkers for age-related macular degeneration. J Biol Chem 2003;278:42027-35.

64 Reme CE, Hafezi F, Marti A, et al. Light damage to retina and retinal pigment epithelium. In: Marmor MF, Wolfensberger, eds. The retinal pigment epithelium. New York: OUP, 1998;Chapter 29:563-86

65 Malek G, Li CM, Guidry C, et al. Apolipoprotein B in cholesterol-containing drusen and basal deposits of human eyes with age-related maculopathy. Am J Pathol 2003;162:413-25.

66 Spraul CW, Lang GE, Grossniklaus HE. Morphometric analysis of the choroid, Bruch's membrane, and retinal pigment epithelium in eyes with age-related macular degeneration. Invest Ophthalmol Vis Sci 1996;37:2724-35.

67 Ciulla TA, Harris A, Kagemann L, et al. Choroidal perfusion perturbations in non-neovascular age related macular degeneration. $\mathrm{Br} J$ Ophthalmol 2002:86:209-13.

68 Jackson GR, Owsley C, Curcio CA. Photoreceptor degeneration and dysfunction in aging and age-related maculopathy. Ageing Res Rev 2002;1:381-96.

69 Holz FG, Gross-Jendroska M, Eckstein A, et al. Colour contrast sensitivity in patients with age-related Bruch's membrane changes. Ger J Ophthalmol 1995;4:336-41.

70 Mackenzie PJ, Chang TS, Scott IU, et al. Assessment of vision-related function in patients with age-related macular degeneration. Ophthalmology 2002; 109:720-9.

71 Cheng AS, Vingrys AJ. Visual losses in early age-related maculopathy. Optom Vis Sci 1993;70:89-96.

72 Brown B, Adams AJ, Coletta NJ, et al. Dark adaptation in age-related maculopathy. Ophthalmic Physiol Opt 1986;6:81-4.

73 Eisner A, Fleming SA, Klein ML, et al. Sensitivities in older eyes with good acuity: eyes whose fellow eye has exudative AMD. Invest Ophthalmol Vis Sci 1987;28:1832-7

74 Owsley C, Jackson GR, Cideciyan AV, et al. Psychophysical evidence for rod vulnerability in age-related macular degeneration. Invest Ophthalmol Vis Sci 2000;41:267-73

75 Haimovici R, Owens SL, Fitzke FW, et al. Dark adaptation in age-related macular degeneration: relationship to the fellow eye. Graefes Arch Clin Exp Ophthalmol 2002;240:90-5

76 Smith VC, Pokorny J, Diddie KR. Color matching and the Stiles-Crawford effect in observers with early age-related macular changes. J Opt Soc Am A 1988:5:2113-21.

77 Frennesson IC, Nilsson SE. Laser photocoagulation of soft drusen in early agerelated maculopathy (ARM). The one-year results of a prospective, randomised trial. Eur J Ophthalmol 1996;6:307-14.

78 Arden GB, Wolf JE. Differential effects of light and alcohol on the electrooculographic responses of patients with age-related macular disease. Invest Ophthalmol Vis Sci 2003;44:3226-32.

79 Arden GB, Wolf JE. Colour vision as a screening test for age-related maculopathy. Br J Ophthalmol 2004;88:1180-5.

80 Curcio CA. Photoreceptor topography in ageing and age-related maculopathy. Eye $2001 ; 15: 376-83$.

81 Kent D, Vinores SA, Campochiaro PA. Macular oedema: the role of soluble mediators. Br J Ophthalmol 2000;84:542-5.

82 Holz FG, Sheraidah G, Pauleikhoff D, et al. Analysis of lipid deposits extracted from human macular and peripheral Bruch's membrane. Arch Ophthalmol $1994 ; 112: 402-6$ 
83 Ramrattan RS, van der Schaft TL, Mooy CM, et al. Morphometric analysis of Bruch's membrane, the choriocapillaris, and the choroid in aging. Invest Ophthalmol Vis Sci 1994;35:2857-64.

84 Blaauwgeers HG, Holtkamp GM, Rutten H, et al. Polarized vascular endothelial growth factor secretion by human retinal pigment epithelium and localization of vascular endothelial growth factor receptors on the inner choriocapillaris. Evidence for a trophic paracrine relation. Am J Pathol 1999;155:421-8.

85 Spilsbury K, Garrett KL, Shen WY, et al. Overexpression of vascular endothelial growth factor (VEGF) in the retinal pigment epithelium leads to the development of choroidal neovascularization. Am J Pathol 2000; 157:135-44.

86 D'Amore PA. Mechanisms of retinal and choroidal neovascularization. Invest Ophthalmol Vis Sci 1994:35:3974-9.

87 Schlingemann RO. Role of growth factors and the wound healing response in age-related macular degeneration. Graefes Arch Clin Exp Ophthalmol 2004;242:91-101.

88 Abdelsalam A, Del Priore L, Zarbin MA. Drusen in age-related macular degeneration: pathogenesis, natural course, and laser photocoagulationinduced regression. Surv Ophthalmol 1999:44:1-29.

89 Sarks SH, Arnold JJ, Sarks JP, et al. Prophylactic perifoveal laser treatment of soft drusen. Aust N Z J Ophthalmol 1996;24:15-26.

90 Little HL, Showman JM, Brown BW. A pilot randomized controlled study on the effect of laser photocoagulation of confluent soft macular drusen. Ophthalmology 1997;104:623-31.

91 Guymer RH, Gross-Jendroska M, Owens SL, et al. Laser treatment in subjects with high-risk clinical features of age-related macular degeneration.
Posterior pole appearance and retinal function. Arch Ophthalmol 1997; 1 15:595-603.

92 Ho AC, Maguire MG, Yoken J, et al. Laser-induced drusen reduction improves visual function at 1 year. Choroidal Neovascularization Prevention Trial Research Group. Ophthalmology 1999;106:1367-73.

93 Frennesson C, Nilsson SE. Prophylactic laser treatment in early age related maculopathy reduced the incidence of exudative complications. Br J Ophthalmol 1998;82:1169-74.

94 Weitzig PC. Photocoagulation of drusen-related macular degeneration. Trans Am Ophthalmol Soc 1994:92:299-306.

95 Holtz FG, Gross-Jendrowska M, Eckstein A, et al. Colour contrast sensitivity in patients with age-related Bruch's membrane changes. Ger J Ophthalmol 1985;4:336-41.

96 Macular Photocoagulation Study Group. Laser photocoagulation of subfoveal neovascular lesions of age- related macular degeneration. Updated findings from two clinical trials. Arch Ophthalmol 1993;111:1200-9.

97 Voutilainen-Kaunisto RM, Terasvirta ME, Uusitupa MI, et al. Age-related macular degeneration in newly diagnosed type 2 diabetic patients and control subjects: a 10-year follow-up on evolution, risk factors, and prognostic significance. Diabetes Care 2000;23:1672-8.

98 Zylbermann R, Landau D, Rozenman Y, et al. Exudative age-related macular degeneration in patients with diabetic retinopathy and its relations to retinal laser photocoagulation. Eye 1997;11:872-5.

99 Deutman AF, Hoyng CB, Meulenduks CFM, et al. The Eyetech Anti-VEGF Study. Ophthalmic Res Suppl 2004 EVER abstract, 2162.

100 Leys A. Lucentis in the treatment of AMD. Ophthalmic Res Suppl. 2004 EVER abstract, 2163. 